\title{
Small non-coding RNAs add complexity to the RNA pathogenic mechanisms in trinucleotide repeat expansion diseases
}

\author{
Eulàlia Martí ${ }^{1,2}{ }^{* \dagger}$ and Xavier Estivill ${ }^{1,2} *{ }^{+}$ \\ 1 Genomics and Disease, Bioinformatics and Genomics Programme, Centre for Genomic Regulation, Barcelona, Spain \\ ${ }^{2}$ Universitat Pompeu Fabra, Barcelona, Spain
}

Edited by:

Hermona Soreq, The Hebrew

University of Jerusalem, Israel

\section{Reviewed by:}

Eran Meshorer, The Hebrew

University of Jerusalem, Israel

Stefan Stamm, University of

Kentucky, USA

\section{*Correspondence:}

Eulàlia Martí and Xavier Estivill,

Genomics and Disease,

Bioinformatics and Genomics

Programme, Centre for Genomic

Regulation, C/Dr. Aiguader, 88,

Barcelona 08003, Spain

e-mail: eulalia.marti@crg.eu;

Xavier.estivill@crg.eu

${ }^{\dagger}$ Eulàlia Martí and Xavier Estivill have

contributed equally to this work.
Trinucleotide-repeat expansion diseases (TREDs) are a group of inherited human genetic disorders normally involving late-onset neurological/neurodegenerative affectation. Trinucleotide-repeat expansions occur in coding and non-coding regions of unique genes that typically result in protein and RNA toxic gain of function, respectively. In polyglutamine (polyQ) disorders caused by an expanded CAG repeat in the coding region of specific genes, neuronal dysfunction has been traditionally linked to the long poly $\mathrm{Q}$ stretch. However, a number of evidences suggest a detrimental role of the expanded/mutant mRNA, which may contribute to cell function impairment. In this review we describe the mechanisms of RNA-induced toxicity in TREDs with special focus in small-non-coding RNA pathogenic mechanisms and we summarize and comment on translational approaches targeting the expanded trinucleotide-repeat for disease modifying therapies.

Keywords: small non-coding RNAs, trinucleotide repeat expansion, RNA-toxicity, miRNA, antisense small RNA

\section{INTRODUCTION}

In the human genome trinucleotide repeats (TNR) are especially abundant in intergenic regions, gene introns and untranslated regions, and translated segments of protein coding genes. Short tandem-TNR have generally less than 30 copies in the normal population (Ellegren, 2004). Abnormal expansions of certain types of TNR result in trinucleotide repeat expansion diseases (TREDs), a group of inherited human genetic disorders involving the nervous system (Table 1; Orr and Zoghbi, 2007). Expansions of triplet repeats occur in coding or non-coding regions of unrelated genes and typically result in late-onset neurological diseases. Disease severity and onset are largely dependent on the expansion length. The pathogenic mechanisms associated to TNR expansions have been an extensive field of research over the last two decades. Different studies have revealed a tremendous complexity in the pathomechanisms, with diverse detrimental effects probably coexisting in cells. This complexity lies beneath the selective affectation of specific cell types in the brain, which is characteristic in each TRED.

The largest group of inherited polyglutamine (polyQ) disorders is caused by expansions of CAG repeats in the open reading frame (ORF) of unique genes, including the Huntington's disease (HD) genes and several spinocerebellar ataxias (SCA) genes. In these diseases the predominant hypothesis has been that the expanded polyQ track confers detrimental properties to the protein, that compromise cell homeostasis. The consequences of polyQ expansion in the HTT protein have been systematically characterized, with detrimental effects in transcriptional activity, vesicle trafficking, mitochondrial function and proteasome activity (Zheng and Diamond, 2012). However, the view of a protein-based toxocity in polyQ disorders has been challenged, as recent findings point to an additional toxic effect of the expanded CAG in the exon 1 of HTT mRNA (Banez-Coronel et al., 2012).

TNR expansions also occur in non-translated regions of selective genes. In myotonic dystrophy (DM1) a CTG expansion in the $3^{\prime}$ UTR of the DMPK gene (50-3000 repeats) leads to neuromuscular degeneration (Brook et al., 1992). A CGG expansion (above 200 repeats) in the $5^{\prime}$-untranslated region (5'UTR) of the FMR1 gene produces fragile $\mathrm{X}$ syndrome, the most common type of mental retardation. Yet, shorter CGG expansions (55-200 repeats) are associated to different pathologies such as fragile $\mathrm{X}$ tremor/ataxia syndrome (FXTAS) and primary ovarian failure (POF; Verkerk et al., 1991; Hagerman and Hagerman, 2004). Expansions occurring in non-translated regions produce RNAs with a toxic gain of function, involving a number of mechanisms, described in subsequent sections.

The recent discovery of repeat associated non-ATG (RAN) translation (Zu et al., 2011) has changed the view of TREDs pathogenesis, as toxic proteins may be also produced from expanded TNR thought to be embedded in non-coding RNAs. RANtranslation from Ataxin8 Oposite Strand (Ataxin8_OS) with an expanded CAG has been shown in different frames, in SCA8 mouse models and in patients with SCA8 ( $\mathrm{Zu}$ et al., 2011). The same study showed RAN-translation across DM1 transcripts, resulting in the accumulation of PolyQ expanded proteins in DM1 mice models myoblasts and cardiomyocites. A similar phenomenon has 


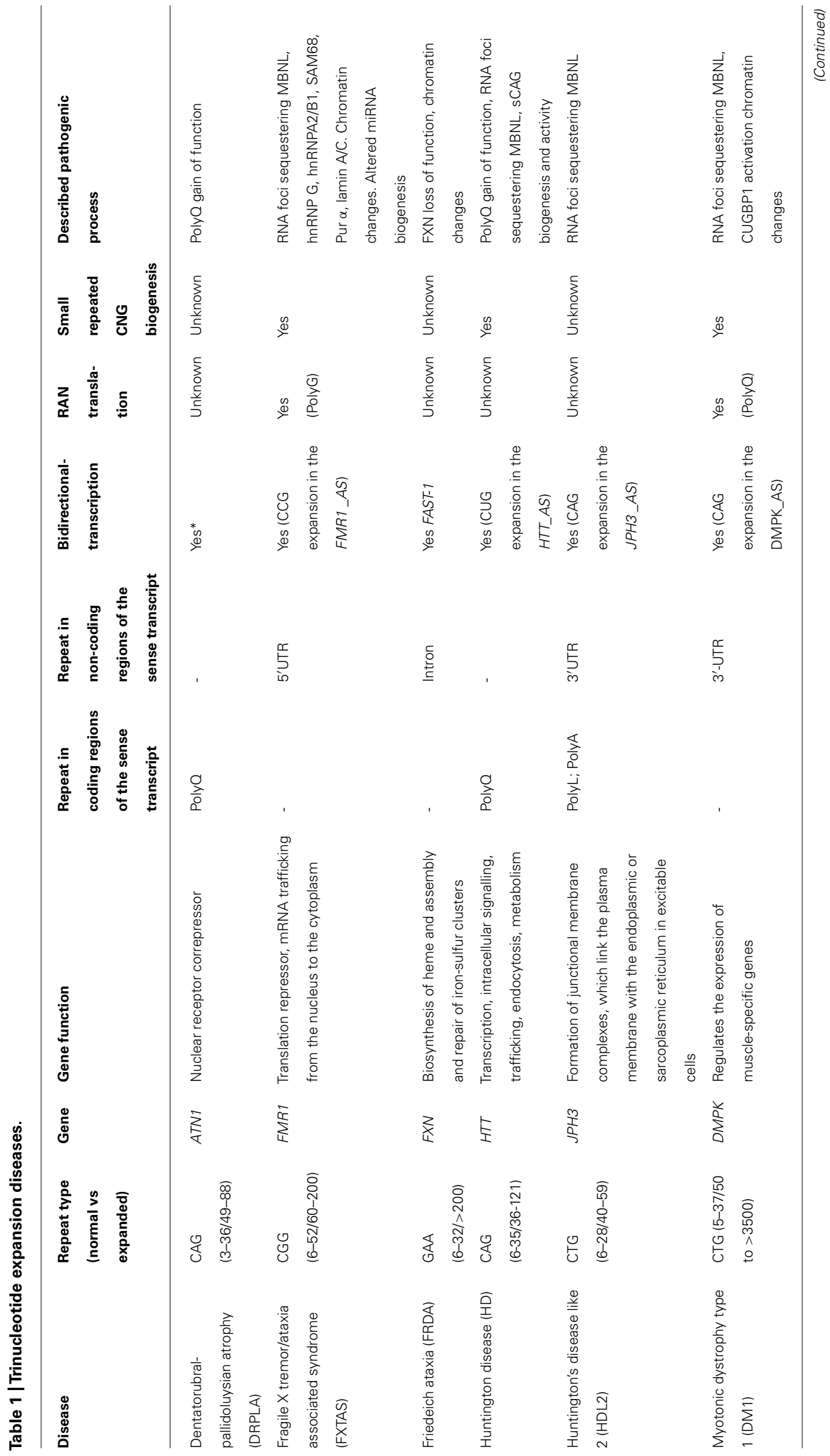




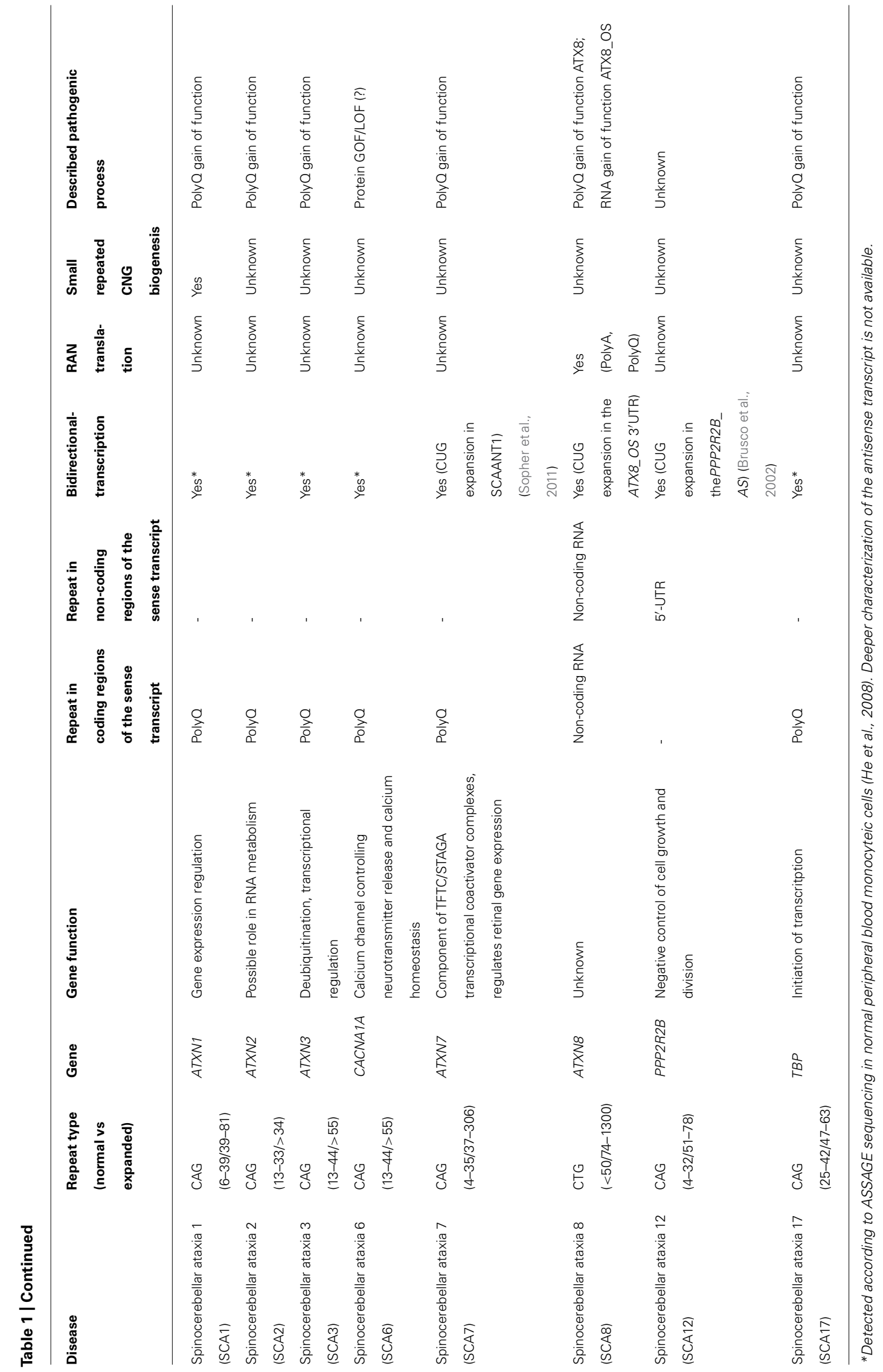


been recently demonstrated in expanded CGG repeats in FMR1 5'-UTR (Todd et al., 2013). A cryptic polyglycine-containing protein (FMRpolyG) was detected accumulating in ubiquitin-positive inclusions in Drosophila, cell culture and mouse disease models, and in brains of patients with FXTAS. The relevance of this mechanism needs to be specifically addressed for each TRED.

In this review we focus on the RNA pathogenic mechanisms in TREDs. We present the existing evidences for RNA binding protein (RBP) sequestration by different expanded TNR and the linked altered biological processes. We address the possible relevance of bidirectional transcritption in TREDs loci and further discuss about the role of small non-coding RNAs in TREDs pathogenesis. Finally, we summarize the latest therapeutic strategies in TREDs, based on selective targeting of the allele with the expanded TNR.

\section{MECHANISMS OF RNA-TOXICITY IN TREDs}

Recent findings indicate that alterations of RNA sequences can lead to abnormal RNA-protein interactions, alteration of protein translation, or RNA interference (RNAi) activation, among other anomalous processes. These altered pathways contribute to disruption of normal cell function and homeostasis, eventually leading to cell degeneration.

\section{TRINUCLEOTIDE REPEAT EXPANSIONS MODIFY ALTERNATIVE SPLICING EVENTS}

In TREDs abnormal expanded TNR RNA-protein interactions results in disrupted protein conformation and inclusion formation. Sequestration of RBP by the expanded TNR leads to a loss of function of such proteins (Figure 1). Muscleblind-like splicing regulator 1 (MBNL1) and Elav-like family member 1 (CUGBP1 or CELF1) are regulators of mRNA splicing that present affinity for CUG and/or CAG repeats. In DM1, long CUG repeats lead to decreased MBNL1 activity and increased CELF1 activity in muscle cells, which results in mis-splicing events in different developmentally regulated genes including the insulin receptor $(I R)$, the chloride channel (CLCN1) and the cardiac tropin T (TNNT2), which explain several aspects of DM1 symptomatology (Ranum and Cooper, 2006; Wheeler and Thornton, 2007).

Aberrant splicing of the bridging integrator-1 (BIN1) premRNA has been recently described in DM1 (Fugier et al., 2011). $\mathrm{BIN} 1$ protein is required for the biogenesis of muscle $\mathrm{T}$ tubules, essential for excitation-contraction coupling. Mis-splicing of BIN1 linked to a loss of function of MBNL1, produces an inactive form of BIN1 protein. While direct interaction of MBNL1 with the CUG repeat depletes MBNL1, increased levels of CEFL1 are the consequence of an indirect effect of CUG expansion involving PKC-pathways (Kuyumcu-Martinez et al., 2007). CELF1 hyperphosphorylation mediated by PKC, leads to its increased stability and activity (Kuyumcu-Martinez et al., 2007). Splicing alterations have been also reported in DM1 and SCA8 brains, with neuronal cells showing MBNL1 nuclear inclusions (Jiang et al., 2004; Daughters et al., 2009; Mykowska et al., 2011). Abnormal splicing of multiple exons in microtubule associated protein tau (MAPT), and exon 7 in the amyloid precursor protein $(A P P)$ and exon 5 in glutamate receptor $N M D A R 1$, have been detected in brains of DM1 patients and mouse models (Jiang et al., 2004; Gomes-Pereira et al., 2007) and analogous splicing alterations have been shown

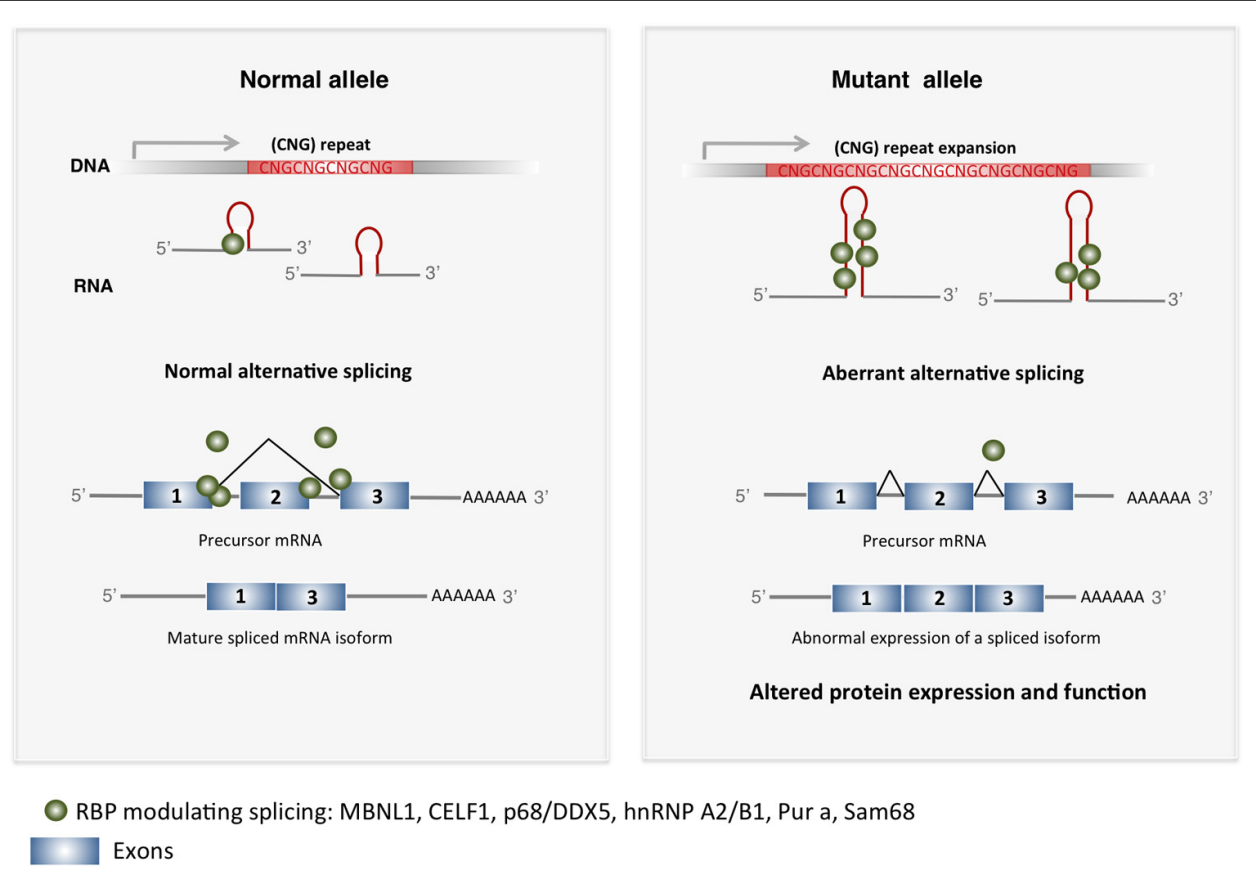

FIGURE 1 | Expanded TNR induce altered mRNA splicing in TREDs. Expanded CNG repeats sequester RBP in the nucleus that modulate exon usage during pre-mRNA maturation, including MBNL1, CELF1, p68/DDX5,
hnRNP A2/B1, Pur a, Sam68. This results in altered alternative splicing in several genes, producing misslocalized or dysfunctional proteins that contribute to pathogenesis in TREDs. 
in SCA8 mice (Daughters et al., 2009) which may explain neurological alterations in these diseases. The relevance of expanded RNA-MBNL1 interaction in DM1 is strengthened in a mouse model expressing an expanded CUG RNA that recapitulates DM1 phenotypes. In this model, partial recovery of the mis-splicing defects is achieved by reestablishing MBNL1 levels. Another recently described repeated-CUG interactor is the p68/DDX5 helicase, which is present in mutant DMPK foci in DM1 (Laurent et al., 2012). p68/DDX5 modifies of MBNL1 splicing activity and has been proposed to influence pathogenicity in DM1.

The CGG expansions in the FMR1 5'UTR causing FXTAS may also sequester MBNL1, which is accumulated as abnormal inclusions in brain of FXTAS patients (Iwahashi et al., 2006). Other RBPs with specific affinity for CGG repeats are Pur- $\alpha$ and hnRNP $\mathrm{A} 2 / \mathrm{B} 1$, which have been found in inclusions in FXTAS models (Jin et al., 2007; Sofola et al., 2007). In addition, CELF1 indirect binding to the CGG repeats through the RBP hnRNP A2/B1, leads to its loss of function (Sofola et al., 2007). Loss of function of Pur- $\alpha$ and hnRNP A2/B1 induce neurological alterations in mice (Khalili et al., 2003), suggesting their participation in FXTAS neuropathology. Recently, loss of function of the splicing factor Sam68 through binding to expanded CGG repeats has been shown in FXTAS patients, contributing to aberrant splicing of the ATPase $A T P 11 B$ and the Survival of Motor Neuron 2, centomeric SMN2 genes (Sellier et al., 2010).
Together, these data indicate that loss of function of RBP that have affinity for expanded TNR is a common mechanism operating in TREDS and further suggest that full characterization of the set of RBP binding to different types of TNR expansions will provide insights into specific pathogenic processes.

\section{TRINUCLEOTIDE-REPEAT EXPANSIONS ALTER mIRNA BIOGENESIS}

The most recent findings suggest that sequestration of RBP by TNR expansions has other consequences in addition to alternative splicing perturbations (Figure 2). MBNL1 and the RNA helicases p68 and p72 influence the activity of proteins involved in microRNA (miRNA) biogenesis (Fukuda et al., 2007; Rau et al., 2011). MBNL1 in normal conditions binds to pre-miR-1 precursor, allowing the normal production of mature miR-1. Depletion of MBNL1 in DM1 permits the activity of the processing regulator LIN28, which binds to pre-miR-1 and promotes $3^{\prime}$-end uridylation, thus resulting in inhibition of pre-miR-1 processing by the endonuclease Dicer. The disruption of the normal pre-miR-1 processing by MBNL1 loss of function results in increased levels of miR-1 targets, including the calcium channel CACNA1C and the gap-junction channel GJA1, which may contribute to the cardiac defects in DM1 (Rau et al., 2011). The modulatory role of p68 and p72 helicases in the miRNA-processing complex (Fukuda et al., 2007) suggest that analogous mechanisms may exist for these proteins.

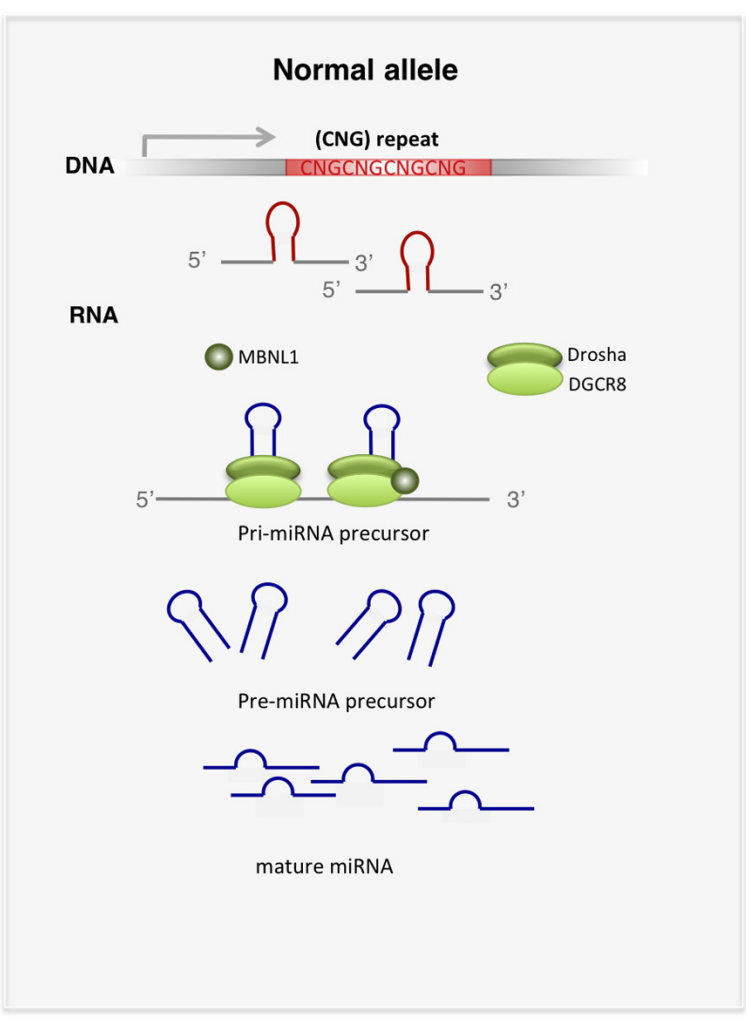

FIGURE 2 | Altered miRNA biogenesis in TREDs. Expanded CNG repeats have affinity for key players of miRNA biogenesis such as DROSHA and DGCR8. Other proteins modulating the activity of DROSHA complex, such as

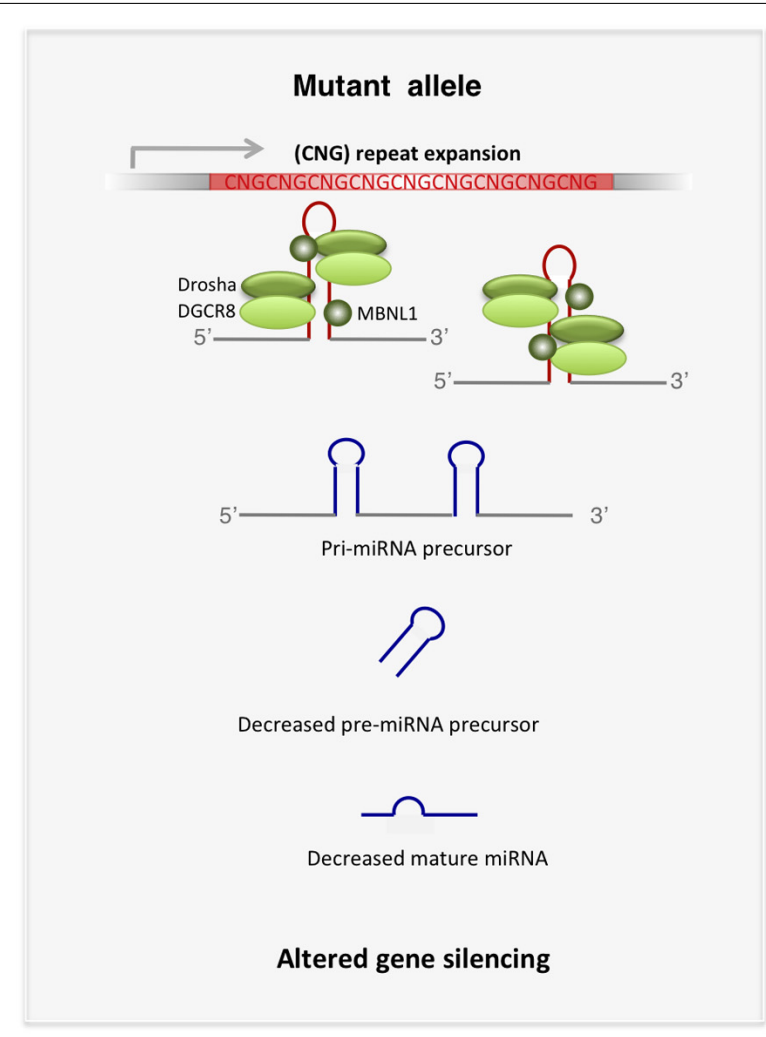

MBNL1, p72 and p68, are also sequestered by expanded TNR. Functional depletion of these proteins leads to decreased production of mature miRNAs, which results in increased expression of miRNA targets. 
Alterations in miRNA biogenesis pathways have been also described in FXTAS (Sellier et al., 2013). The hairpin structure of the expanded CGG in the FMR1 5'UTR mRNA mimics the structure of the miRNA-precursors (pri-miRNAs). DGCR8 and its partner DROSHA, key players in miRNA-precursor processing, are sequestered by CGG-RNA repeats (Figure 2). Depletion of these processors compromises the biogenesis of many miRNAs, thus triggering downstream detrimental gene expression perturbations, which likely contribute to FXTAS pathogenesis. However, this mechanism may be tissue-dependent, as small RNA profiling in peripheral blood of FXTAS patients does not reveal a general miRNA downregulation (Alvarez-Mora et al., 2013).

General perturbations in miRNA biogenesis result in altered mature miRNAs expression and subsequent modifications of gene silencing, which likely contribute to disrupted cell homeostasis in TREDs.

\section{BIOGENESIS AND ACTIVITY OF SMALL REPEATED CNG IN TREDS SENSE TRANSCRIPTS}

The hairpin structure of expanded CNG repeats (Galka-Marciniak et al., 2012) constitutes a substrate for Dicer, an endonuclease involved in miRNA biogenesis that excises RNA precursors to generate the mature short miRNA (Figure 3). Dicer recognizes the expanded triplet and cleaves it, producing small repeated RNAs ( $\mathrm{sCNG}$ ). In vitro approaches demonstrated that single stranded CGG-RNA constructs are cleaved by Dicer, producing short CGG-RNAs of approximately 21 nt (sCGG; Handa et al., 2003). Recombinant Dicer also cleaves long transcripts containing other types of long CNG repeats (CAG, CUG, CCG; Krol et al., 2007). Importantly, the Dicer-dependence of sCNG biogenesis has been demonstrated in fibroblasts of patients with DM1 (sCUG), HD (sCAG) and SCA1 (sCAG; Krol et al., 2007). In this study the authors further showed that $\mathrm{SCNG}$ were active as transcriptional inhibitors, since they downregulated the expression of transcripts with complementary target sequences. This inhibitory activity was dependent on Ago2, a key member of the RNA silencing machinery (Krol et al., 2007).

The relevance of sCNG in TREDs pathogenesis has been recently addressed in HD (Banez-Coronel et al., 2012). This study confirmed the biogenesis of sCAG in a neuronal cell model expressing expanded HTT exon-1, and in brain samples of patients with $\mathrm{HD}$ or the R6/2 HD mouse model. Importantly, the fraction of small RNAs (sRNAs) derived from cells expressing expanded HTT exon-1 produced neuronal death. Both the biogenesis and the toxic activity of sCAG were dependent on Dicer. Similarly, transfection of sRNAs isolated from the striatum and cortex of patients with HD induced significant neuronal toxicity. This toxic effect was prevented by oligonucleotides complementary to short CAG, strongly suggesting a detrimental effect of sCAG. Furthermore, toxicity may depend on downstream silencing effects, as HTT exon-1-derived sCAG were loaded onto Ago2 complexes and knocking-down of Ago2 prevented damage. However, the sequence/structure requirements for effective silencing of sCAG-targets remain to be resolved, since similar moderate inhibition was detected in luciferase assays performed with targets harboring a perfect sCAG-complementary CTG repeat or a CAG repeat that offers an interrupted sCAG target site. Whether the detrimental properties of sCAG include silencing effect through mRNA degradation and/or translational repression, or perturb gene expression networks through other mechanisms, remains to be determined. Interestingly, this study shows that the effect of sCAG-RNAs differed depending on the cell type, with high toxicity detected in BDNF-differentiated neuroblastoma cells. In this scenario, sCAG activity may provide a mechanism contributing to tissue selective affectation. The relevance of sCNG biogenesis and activity in other TREDs is an interesting field for future studies.

\section{BIDIRECTIONAL TRANSCRIPTION IN TREDS LOCI PRODUCE NEW PATHOGENIC PLAYERS}

Much of the transcriptome is transcribed in both directions (Chen et al., 2004). While recent data suggest that only a small part of the sense transcript produces proteins (Derrien et al., 2012), the anti-sense transcripts, normally less abundant, are involved in the regulation of gene expression (He et al., 2008; Morris et al., 2008; Yu et al., 2008; Batra et al., 2010). Bidirectional transcription has been detected in many TREDs loci including, DM1, SCA8, FXTAS, SCA7, HDL2, and HD, suggesting a role in disease pathogenesis (Table 1; Cho et al., 2005; Ladd et al., 2007; Batra etal., 2010; Chung et al., 2011; Sopher et al., 2011; Wilburn etal., 2011; Seixas etal., 2012). Thus, TREDs pathogenic mechanisms typically associated with expanded toxic RNA may be complemented with those induced by abnormal expanded peptides that result from coding-antisense transcripts or by a complementary non-coding expanded RNA. For instance, in SCA8, the progressive cerebellar degeneration inducing ataxia is the consequence of a CUG expansion in the 3' end of the non-protein coding Ataxin $80 S$ mRNA (Koob et al., 1999; Day et al., 2000). This led to the conclusion that the pathogenic mechanism was related with an expanded CUG-RNA toxic gain of function. Subsequently, bidirectional transcription was demonstrated in transgenic mice expressing the entire human locus with either normal or expanded CTG allele (Moseley et al., 2006). A progressive neuronal loss was found in the lines expressing expanded CUG, with concomitant co-expression of two transcripts in opposite directions. The sense transcript produced a non-coding CUG-expanded transcript (Ataxin 8OS) and an antisense transcript resulted in a CAG expansion that was translated into a highly enriched polyQ track (Ataxin 8$)$. Intranuclear inclusions immunopositive for anti-polyQ antibodies, which are typical from PolyQ diseases and CUG foci formation co-localizing with MNBL1 were detected in cerebellar cells of the mouse model and patients with SCA8 (Daughters et al., 2009). Thus, both RNA and protein toxic gain of function may account for SCA8 pathogenesis.

A similar process could account for HDL2 pathogenesis that is caused by a CUG/CAG repeat expansion at the Juctophilin-3 (JPH3) locus (Holmes et al., 2001), The alternatively spliced forms in the $\mathrm{JPH} 3$ gene place the CUG expansion in the polyleucine or polyalanine ORFs or in the $3^{\prime} U T R$. A $J P H 3$ transcript with expanded CUG repeats produce RNA foci that co-localize with MNBL1 and induces cell toxicity (Rudnicki et al., 2007). The existence of an anti-sense CAG transcript in the JPH3 locus was recently demonstrated, which may account for the detected polyQ proteianceous inclusions (Wilburn et al., 2011). 
DNA

\section{(CNG) repeat expansion}
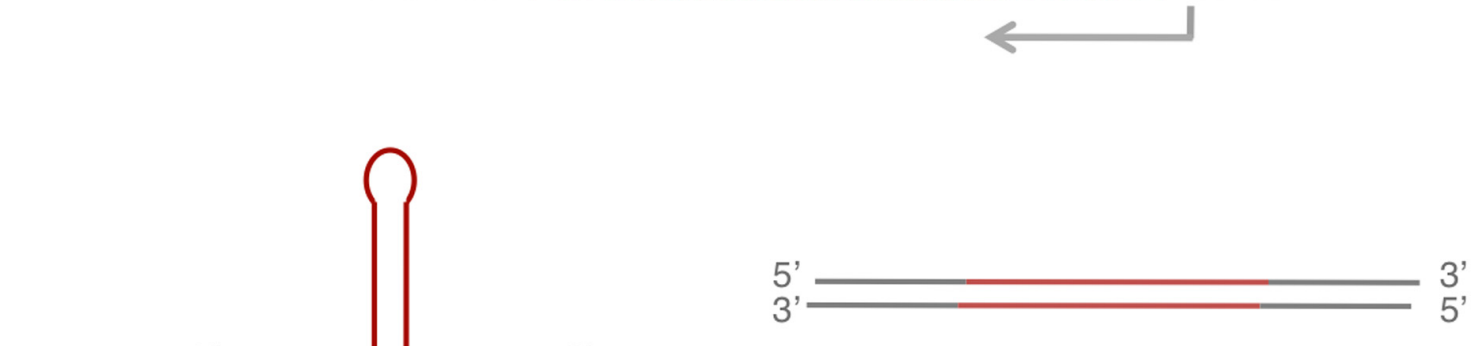

RNA

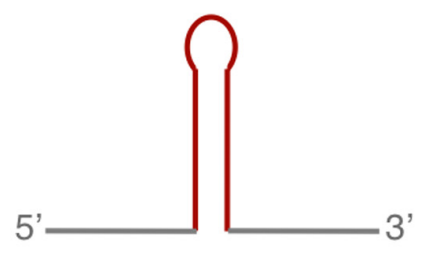

Sense CNG-expanded mRNA hairpin

Sense/anti-sense double stranded CNG-expanded mRNA
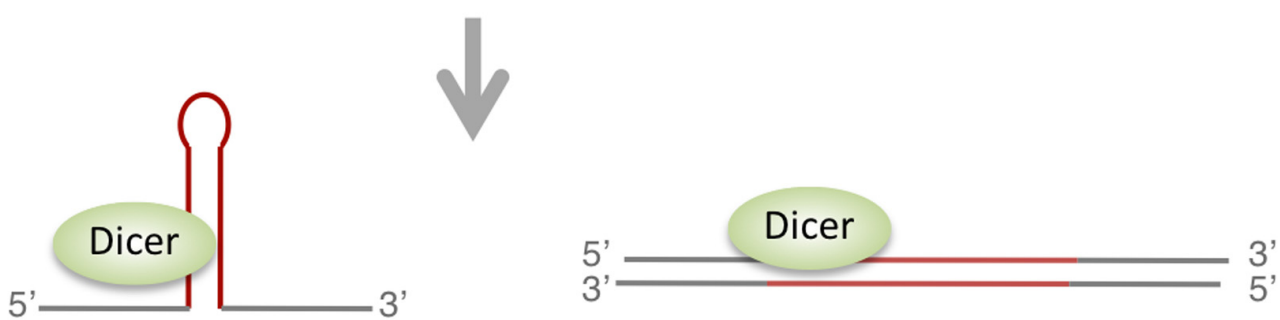

Dicer processing

RISC

Ago2

target mRNA

AAAA

\section{Gene silencing}

FIGURE 3 | Biogenesis and activity of sCNG in TREDs. TNR expansions produce hairpin-like structures that are recognized and cleaved by Dicer to form small RNAs with repeated TNR (sCNG).

Bidirectional transcription though the expanded TNR offers another source of sCNG, where perfectly complementary double stranded mRNAs with expanded TNR are cleaved by Dicer to form sCNG. sCNG are incorporated into the RISC complex and silence genes with partial or perfect complementarity.
Anti-sense transcripts spanning the CGG repeat have been described in the FMR1 locus (FMR1AS) in human lymphoblastoma cells (Ladd et al., 2007). FMR1AS is spliced, processed and exported from the nucleus. The regulation of FMR1AS expression is dependent on CGG expansion size; being silenced in full
CGG mutations (CGG > $200 \mathrm{nt}$ ), similar to the FMR1 sense transcript. A recent study suggested that elevated expression levels of the sense and antisense expanded FMR1 involving mitochondrial dysfunction participate in parkinsonism phenotype that is associated with CGG-repeat moderate expansions (Loesch et al., 2011). 
Thus, both FMR1 and ASFMR1 may contribute to the variable phenotypes associated with the CGG repeat expansion.

Anti-sense transcription at the DM1 locus has also been reported (Cho et al., 2005). Both sense and antisense transcripts extending across the CAG repeat were found in independent nuclear foci in a mouse model carrying $>1,000$ CTG repeats in the DM1 locus and in human tissues (Huguet et al., 2012).

HTT anti-sense (HTTAS) transcripts have been identified that contain the repeated CAG track (Chung et al., 2011). Repeat expansion reduces HTTAS promoter efficiency, and therefore HTTAS expression is reduced in the brain of HD patients. Through knocking down the HTTAS transcript the authors demonstrated its regulatory activity on HTT expression. The relevance of this regulatory mechanism in HD has not been addressed. However, a possibility exists that HTTAS provides an expanded CUG-based pathogenic mechanism.

One interesting mechanism derived from anti-sense transcription of genes containing TNR expansions is the activation of silencing mechanisms (Figure 3). Complementary repeats can form double-stranded structures compatible with endonuclease Dicer slicing activity. This results in the formation of short repeated RNAs that are incorporated into the RISC complex, possibly driving downstream gene silencing with detrimental consequences. This mechanism has been proven in a DM1 Drosophila model, in which the toxic effect of an expanded CUG track was largely enhanced if co-expressed with a CAG expansion. The co-expression of sense and anti-sense transcripts lead to the formation of repeat-derived small interfering RNAs in a process dependent of Dicer-2 and Ago-2 (Yu et al., 2011). Similarly, flies models expressing CAG/CUG -100 nt double stranded RNAs (Lawlor et al., 2011) showed a Dicer 2-dependent progressive neurodegenerative phenotype.

From these results it seems clear that small double stranded RNAs are detrimental for neuronal cells. However, the relevance of bidirectional transcription derived-siRNA in human disease needs to be proven, as the expression of antisense transcripts is normally low, which may limit the formation of these products.

In summary, bidirectional transcription through repeat regions of TREDs genes likely increases the complexity of the pathogenic mechanisms underlying the disease process, including the sequestration of different RBP and the biogenesis of small repeated TNR RNAs with silencing activity.

\section{EVIDENCES FOR RNA TOXICITY IN POLYO DISORDERS}

Although in polyQ diseases pathogenesis has been traditionally linked to altered function of the protein, a number of evidences suggest a complementary detrimental role of the expanded RNA.

In vitro structure determinations of expanded CAG repeats in the mRNA context of the HTT, ATXN1-3, ATN1 and AR genes that cause different polyQ diseases (Table 1) show compatibility with double stranded hairpin formation (Galka-Marciniak et al., 2012). Biochemical studies further suggested that MBNL1 has similar affinity for RNA containing either CUG or CAG repeats (Yuan et al., 2007). Although CAG expansions in polyQ diseases occur in the protein coding sequence, nuclear RNA inclusions accumulating MBNL1 have been detected in fibroblasts of patients with ATXN3 and HD (de Mezer et al., 2011;
Mykowska etal., 2011). Alternative splicing defects similar to those observed in DM1 have been shown in these cells, suggesting that splicing alterations are likely the consequence of MBNL1 sequestration.

Expanded CAG repeats were shown to induce in vivo toxicity at the RNA level in Drosophila, C. elegans and mouse models. The in vivo evidence for repeated CAG RNA toxicity was first obtained in a Drosophila model of SCA3 (Li et al., 2008). The expression of untranslated CAG repeats of pathogenic length led to neurodegeneration in the absence of a mutant polyQ protein. The expression of translated CAA or interrupted CAG repeats resulted in a less severe phenotype than the expression of translated pure CAG repeats, which supported the importance of RNA structure for toxicity.

The CAG repeat toxicity at the RNA level was also demonstrated in a worm system (Wang et al., 2011). Both CAG and CUG repeats of pathological length were shown to form nuclear foci, in which the mutant transcript colocalized with the nematode ortholog of MBNL1, CeMBL. The disease phenotype was partially reversed by CeMBL over-expression.

The expression of untranslated long CAG repeats (200 copies) was also shown to be deleterious in transgenic mice (Hsu et al., 2011). Mice expressing EGFP transcripts with long CAG repeats in the $3^{\prime}$-UTR developed electrophysiological, histological and behavioral aberrations in the muscle. Detection of nuclear RNA foci in muscle cells in this model (Hsu et al., 2011) and in the striatum of the YAC128 HD mouse model expressing full-length human HTT (Pouladi et al., 2012) further suggests toxicity through expanded CAG-RNA.

These data indicate that cell failure in polyQ diseases may be the result of both an abnormal function of the protein harboring the expanded glutamine and the altered properties of the expandedCAG RNA. The secondary structure of the CAG-repeat in each gene context and the dynamic expression and activity of RBP may provide specific pathogenic scenarios for cell dysfunction.

\section{miRNAs PERTURBTIONS IN TREDs}

MicroRNAs are small RNA molecules of 20-24 nucleotides that generally inhibit the expression of target mRNA, by a mechanism involving mRNA degradation, translational inhibition or a combination of the two (reviewed in Esteller, 2011). miRNAs biogenesis involves processing of a primary transcript in the nucleus (primiRNAs) by the Drosha/DGCR8 microprocessor. This generates a precursor miRNA (pre-miRNA) that is exported to the cytoplasm by exoprtin-5, where the endonuclease Dicer cleaves it to release the double-stranded miRNA. One of these strands preferentially loads onto an RNA induced silencing complex (RISC), while the other strand is usually degraded. In animals, miRNAs recognize their targets through complementarity with the seed sequence (nucleotides $2-8$ of the $5^{\prime}$ end of the miRNA). Hundreds of mRNA targets could exist per miRNA family and at least $30 \%$ of the mRNAs are targeted by miRNAs (O'Carroll and Schaefer, 2013).

miRNAs are fine-tuners of gene expression with key roles in the central nervous system function and development. The first evidences for a major role of miRNAs in neurons involved in vitro and in vivo models of loss of function of Dicer, a key limiting 
endonuclease in miRNA biogenesis. Dicer depletion disrupts the development of the CNS, with clear effects on brain morphology and cell-type specification and differentiation. Conditional knocking-down of Dicer in specific neuronal populations in adult mice further suggests a role of miRNAs in postmitotic longterm neuronal maintenance (Kim et al., 2007; Schaefer et al., 2007; Haramati et al., 2010). Furthermore, conditional loss of Dicer in astrocytes and oligodendrocyes causes neuronal dysfunction and degeneration (Shin et al., 2009; Tao et al., 2011). DGCR8 is one of the genes whose heterozygous deletion results in DiGeorge syndrome (Shiohama et al., 2003) with the majority of patients showing heart defects and developmental problems. The description of DGCR8 as key component of the microprocessor (Gregory et al., 2004) highlighted that defects in miRNA biogenesis likely underlie developmental defects. Haploinsufficiency of the microprocessor member DGCR8 also compromises neuronal viability in mice (Stark et al., 2008).

Perturbations of miRNA pathways have emerged as effectors of CNS damage, contributing to impaired cell homeostasis and neuronal death. MiRNAs deregulation produces alterations in the transcriptome that impact brain function, with consequences in neurodegeneration-relevant pathways, including inflammation, oxidative stress and mitochondrial integrity. The causes of miRNA expression deregulation are diverse, including changes in the activity of transcription factors or disease-associated genes and/or alterations in miRNA biogenesis or stability (Packer et al., 2008; Martí etal., 2010). Ischemia, excitotoxicity, oxidative stress or aging are examples of harmful stimuli producing alterations in the coding and non-coding transcriptome (Persengiev et al., 2011; Xu et al., 2012).

Several studies point to an involvement of miRNAs in the pathogenicity associated to TREDs. The toxicity of Ataxin-3 is enhanced upon Dicer ablation in Drosophila and human cell models. The administration of a pool of sRNAs restored Ataxin-3 toxic effect, suggesting a protective role of miRNAs (Bilen et al., 2006). Supporting a protective role of miRNAs in polyQ diseases, miR$34 \mathrm{~b}$ was shown to mitigate the toxicity of Ataxin-3 in a Drosophila model (Liu et al., 2012).

The activity of disease-associated genes has emerged as one of the causes for miRNA deregulation in TREDs. Mutant HTT protein interacts with Ago2 in the P-bodies, and HTT depletion impairs miRNA mediated gene silencing (Savas et al., 2008). Strong miRNA deregulation has been detected in HD that may be in part associated with altered activity of the RE1-silencing transcription factor (REST). The expanded HTT polyQ track impedes sequestration of REST by wild-type HTT in the cytoplasm, therefore allowing its translocation to the nucleus. Mislocalization in the nucleus permits REST binding to RE1 repressor sequences thus decreasing neuronal gene expression, which triggers neuronal dysfunction. Several miRNAs with RE1 upstream binding sites are down-regulated in HD, including miR-9/miR-9* (Packer et al., 2008). A negative feed-back loop was proposed to occur in HD, involving the activity of REST-silencing complex that is regulated through the effect of miR9 and miR-9* on REST and Co-REST, respectively (Packer et al., 2008). High-throughput sequencing analysis has revealed strong miRNA expression deregulation in the striatum and frontal cortex of patients with HD (Martí et al.,
2010). A significant enrichment of down-regulated miRNAs harboring upstream RE1 or P53 binding sites was also reported in this study, suggesting a major role of these transcriptional modulators in miRNA deregulation.

In another example, Ataxin-2 has been recently identified as a component of the miRNA pathway to regulate synapsespecific long-term-plasticity. This targets the putative relevance of ataxin-2/miRNAs in spinocerebellar ataxia neurodegeneration (McCann et al., 2011).

Significant miRNA deregulation has been also detected in pre-symptomatic versus symptomatic SCA1 mouse model cerebellum, which suggests a role of miRNAs in the evolution of the disease (Rodriguez-Lebron et al., 2013). In addition, the miRNA transcriptome has been also characterized in the muscle of a Drosophila model of DM1, expressing CTG repeats alone (Fernandez-Costa et al., 2013). Among the downregulated miRNAs, miR-1, miR-7, and miR-10 were confirmed in muscle of patients with DM1. Interestingly, over-expression of miR-10 extended the lifespan of CUG-expressing flies, suggesting a role in the disease.

Deregulation of miRNA specifically targeting dosage-sensitive disease genes may highlight their relevance as pathogenic biomarkers, which could be selectively targeted in therapeutic strategies. Dentatorubral-pallidoluysian atrophy (DRPLA) is caused by a CAG/polyQ expansion in DRPLA gene/protein, respectively. miR200b and miR-429 target REPRE mRNA, whose protein product binds to DRPLA protein. Overexpression of REPRE induces DRPLA mislocalization. Thus, expression levels of miR-200b and miR-429 could potentially contribute to DRPLA (Yanagisawa et al., 2000; Karres et al., 2007). In another example, miR-886-3p targets the frataxin gene $(F X N)$ that carries an intronic GAA. TTC triplet repeat expansion in Friedeich ataxia (FRDA; Mahishi et al., 2012). FXN mRNA and protein are decreased in FRDA. The authors found increased levels of miR-886-3p in blood and cells of patients with FRDA and further demonstrated that inhibition of miR-886$3 p$ resulted in increases of FXN mRNA and protein. In addition, miR-19, miR-101 and miR-130 regulate Ataxin 1 (ATXN1) that causes spinocerebellar ataxia 1 (SCA1), when presenting a CAG expansion (Lee et al., 2008). The authors showed that inhibition of the activity of these miRNAs enhanced the cytotoxic activity of ATXN1 with an expanded polyQ in human cells, suggesting a miRNA mechanism modulating pathogenesis. More recently, it has been shown that, miR-144 and miR-101 play a central role in modulating the levels of ATXN1 (Persengiev et al., 2011). In SCA1 patients and aging the levels of these miRNAs are increased, suggesting a role in neurodegeneration. Finally, the $3^{\prime}$ UTR of the FMR1 mRNA is targeted by miR-101, miR-129-5p, and miR-221 (Zongaro et al., 2013). Downregulation of miRNAs has been generally detected in the brain of patients with FXTAs (Sellier et al., 2013) and miR-221 is also downregulated in peripheral blood of males with FXTAS (Alvarez-Mora et al., 2013). Thus, deregulation of certain miRNAs may contribute to upregulation of expanded FMR1, which has been shown to participate in FXTAS pathogenesis.

These data indicate that altered expression of specific miRNAs may contribute to TREDs pathogenesis, directly perturbing the expression of dosage-sensitive genes that are essential in the 
maintenance of cell homeostasis. The dynamics of miRNA alterations may define the relevance of miRNA-pathways in disease evolution.

\section{THERAPEUTIC APPROACHES TARGETTING RNA-TOXICICITY}

Several therapeutic targets in polyQ diseases such as HD involve the intervention of pathways perturbed by mutant polyQ proteins, including histone acetylation, excitotoxicity and oxidative stress (Clabough, 2013). Mutant HTT inhibits acetyltransferases, resulting in reduced levels of acetylated histones (Gray, 2010) Inhibition of histone deacetylase activity (HDACs) has been proposed as a therapeutic approach, alleviating altered gene expression produced by diminished acetyltransferase activity (Steffan et al., 2001; Gray, 2010). In addition, mitochondrial impairment and excitotoxicity have been involved in neuronal death in HD. Administration of antioxidants such as Coenzyme Q10 slow striatal atrophy in mouse models of HD (Beal, 2002) and delivery of growth factors and cytokines modify neuronal degeneration and prevents excitotoxic deficits in murine HD models (Mittoux etal., 2000; Perez-Navarro etal., 2000; de Almeida etal., 2001). Other strategies involve lowering the amount of mutant polyQ protein by reducing its production (see below) or enhancing its clearance. In this line, increased mutant HTT protein turnover in a mouse model improves disease outcome (Southwell et al., 2009).

Although targeting the mutant/expanded polyQ protein or its downstream pathogenic effectors improves disease readouts, these strategies may not impede expanded TNR RNA toxicity. Approaches aimed at blocking protein and/or RNA toxicity include the use of antisense oligonucleotides (ASOs) or RNAi (short hairpin RNAs, shRNA, double stranded siRNA or modified single stranded siRNAs), targeting the expression of the mutant gene (Sah and Aronin, 2011; Watts and Corey, 2012; Figure 4). RNAi using shRNA against mutant TREDs gene mRNA and protein have been successfully used in vivo. Intrastriatal adenoviral-delivery shRNA targeting mutant human HTT resulted in improved neuropathology and behavioral deficits in HD mouse models (Harper et al., 2005; Rodriguez-Lebron et al., 2005). Davidson's lab later showed that miRNA expression systems to inhibit HTT were more efficient, overcoming unspecific toxic effects induced by shRNA expressing vectors (McBride etal., 2008; Boudreau et al., 2011). The therapeutic potential of 2'-O-(2-methoxy)ethyl modified ASOs targeting human HTT has been recently addressed (Kordasiewicz et al., 2012). The intracerebral transient infusion of these ASOs resulted in the RNAse $\mathrm{H}$ mediated degradation of the human HTT mRNA, in transgenic mouse models of HD (Kordasiewicz et al., 2012). Importantly, transient HTT reduction resulted in sustained motor and histopathological phenotypic reversal in the HD rodent models.

Because multiple studies suggest that reducing the expression of the wild-type allele may have deleterious consequences, selective targeting of the expanded allele should be optimal (Omi et al., 2005; Godin et al., 2010; Huang et al., 2011). In polyQ diseases, single-nucleotide polymorphisms (SNPs) linked to repeat expansions that distinguish wild-type from mutant alleles offer possibilities for specific targeting by RNAi. SNP targeting has been shown in HD (Schwarz et al., 2006; Carroll et al., 2011), SCA3 (Li et al., 2004) and SCA7 (Scholefield et al., 2009). Low frequency of allele-distinguishing SNPs in the human population limits this strategy. However, several authors have shown that targeting several specific SNPs can be applied to the majority of HD patients (Lombardi et al., 2009; Pfister et al., 2009; Warby et al., 2009).

Other potential therapeutic strategies in polyQ diseases, are based on the use of several types of modified single stranded ASOs that target the CAG expansion in the mutant HTT or ATXN3 mRNA, while preserving the normal function of the wild type allele (Hu et al., 2009a,b,c; Gagnon et al., 2010; Fiszer et al., 2012; Yu et al., 2012). The longer CAG track in the mutant allele offers more binding sites for the complementary ASOs (Figure 4). In addition, the RNA structures of the expanded CAG that differ from those of the wild type allele (de Mezer et al., 2011; Krzyzosiak et al., 2012), may offer distinctive feature for preferential recognition of the mutant allele. In these studies, single-stranded ASOs containing locked nucleic acid (LNA) or peptide nucleic acid have been shown to selectively block the expression of mutant HTT at the protein level. This effect was not associated with extensive HTT mRNA degradation and LNA ASOs were shown to form stable structures with the target RNA. Although expanded RNA toxicity in HD has not been addressed, the formation of stable LNA ASOs : RNA duplexes has also the potential to block expanded CAG toxic effects in HTT mRNA.

Several studies have demonstrated a similar therapeutic potential of a CAG-repeat antisense or morpholino targeted to expanded-CUG in the DMPK mRNA (Mulders et al., 2009). In cell myoblast-myotube and patient cell models a 2'-O-methylphosphorothioate-modified (CAG)7 ASO silenced DMPK expression and reduced the ribonuclear aggregates. Intramuscular administration of these ASO in a DM1 mouse model further reduced expanded RNA toxicity (Mulders et al., 2009). In another study, a morpholino anti-sense (CAG) 25 was shown to block the interaction of MBNL1 with the expansion in a mouse model, further dispersing nuclear RNA foci, preventing alterations in alternative splicing and preventing RNA toxicity. More recently, it has been shown that systemic administration of ASOs effectively knocked down the expression of nuclear retained-transcripts containing expanded CUG in the muscle, thus correcting the physiological, histopathological and transcriptional alterations associated to this DM1 model (Wheeler et al., 2012).

Together, these data suggest that in TREDs, targeting the expression and activity of the expanded allele both at the RNA and protein levels is a promising therapeutic strategy.

\section{CONCLUSION}

RNA toxicity is a process underlying pathogenicity in TREDs, with TNR expansions occurring in both coding and non-coding regions of specific genes. Sequestration of transcriptionally active RBP, and RBP participating in miRNA biogenesis result in direct and indirect perturbations of the coding-transcriptome, which likely contribute to cell dysfunction. Full characterization of the repertoire of RBP in different types of TNR expansions is essential to understand common detrimental pathways in etiologically diverse neurological disorders. Studies that take into consideration the gene context may provide hints to understand disease specific aspects. 


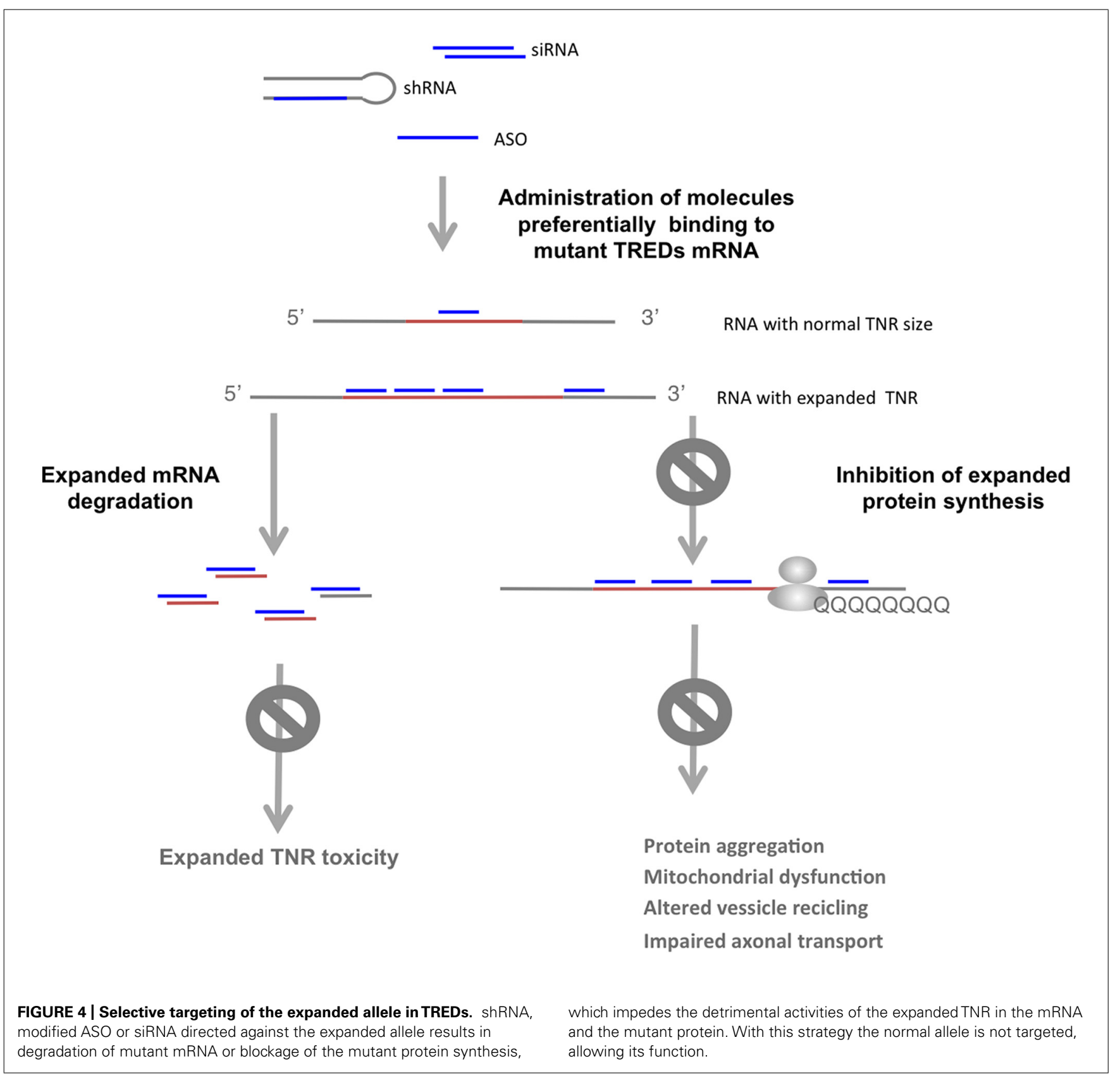

The biogenesis and activity of sCNG may contribute to TREDs pathogenesis. The gene silencing activity of these species likely trigger downstream detrimental effects, which may differ, depending on the cell type. This mechanism may complement the damaging activity of expanded protein and/or expanded RNA. Whether sCNG mechanisms are only related with gene silencing or present other activities and the real importance of sCNG mechanisms in each TRED remain to be determined.

In each TRED, the mechanistic bases for tissue specificity, with particular affectation of selective neuronal types, remain largely unknown. The different RNA-based pathogenic processes provide a number of scenarios that may underlie this specificity. These include the dynamic expression and cellular

and subcellular localization of RBP, the amount of expression of the sense and anti-sense transcripts spanning the expanded TNR in each cell context, the regulation of the biogenesis and activity of sCNG in different brain areas and/or the temporal and spatial primary and secondary perturbations of the miRNA transcriptome.

The mechanistic complexity in TREDs stresses the need of additional studies to dissect the relative relevance of expanded proteinRNA-, and/or sRNAs-mechanisms in each disease. In this context, the use of modified ASOs or siRNA directed to the expanded TNR has the potential to block deleterious effects of expanded full-length RNA and derived sCNG, with concomitant inhibition of expanded protein expression. 


\section{ACKNOWLEDGMENTS}

This work was supported by the Spanish Government and FEDER (Fondo Europeo de Desarrollo Regional): PN de I+D+I 2008-2011 PI081367 and PN de I+D+I 2012-2015 PI11/02036, Instituto Carlos III -ISCIII-, Subdirección General de Evaluación y Fomento de la Investigación (to Eulàlia Martí), SAF200800357 Ministerio de Economia y competitividad, ISCIII (to Xavier Estivill). The Spanish Government supports Eulàlia Martí (Programa Miguel Servet).

\section{REFERENCES}

Alvarez-Mora, M. I., Rodriguez-Revenga, L., Madrigal, I., Torres-Silva, F., MateuHuertas, E., Lizano, E., et al. (2013). MicroRNA expression profiling in blood from fragile X-associated tremor/ataxia syndrome patients. Genes Brain Behav. 12, 595-603. doi: 10.1111/gbb.12061

Banez-Coronel, M., Porta, S., Kagerbauer, B., Mateu-Huertas, E., Pantano, L., Ferrer, I., et al. (2012). A pathogenic mechanism in Huntington's disease involves small CAG-repeated RNAs with neurotoxic activity. PLoS Genet. 8:e1002481. doi: 10.1371/journal.pgen.1002481

Batra, R., Charizanis, K., and Swanson, M. S. (2010). Partners in crime: bidirectional transcription in unstable microsatellite disease. Hum. Mol. Genet. 19, R77-82. doi: $10.1093 / \mathrm{hmg} / \mathrm{ddq} 132$

Beal, M. F. (2002). Coenzyme Q10 as a possible treatment for neurodegenerative diseases. Free Radic. Res. 36, 455-460. doi: 10.1080/10715760290021315

Bilen, J., Liu, N., Burnett, B. G., Pittman, R. N., and Bonini, N. M. (2006). MicroRNA pathways modulate polyglutamine-induced neurodegeneration. Mol. Cell 24, 157-163. doi: 10.1016/j.molcel.2006.07.030

Boudreau, R. L., Spengler, R. M., and Davidson, B. L. (2011). Rational design of therapeutic siRNAs: minimizing off-targeting potential to improve the safety of RNAi therapy for Huntington's disease. Mol. Ther. 19, 2169-2177. doi: 10.1038/mt.2011.185

Brook, J. D., McCurrach, M. E., Harley, H. G., Buckler, A. J., Church, D., Aburatani, H., et al. (1992). Molecular basis of myotonic dystrophy: expansion of a trinucleotide (CTG) repeat at the $3^{\prime}$ end of a transcript encoding a protein kinase family member. Cell 69, 385. doi: 10.1016/0092-8674(92)90154-5

Brusco, A., Cagnoli, C., Franco, A., Dragone, E., Nardacchione, A., Grosso, E., et al. (2002). Analysis of SCA8 and SCA12 loci in 134 Italian ataxic patients negative for SCA1-3, 6 and 7 CAG expansions. J. Neurol. 249, 923-929. doi: 10.1007/s00415-002-0760-y

Carroll, J. B., Warby, S. C., Southwell, A. L., Doty, C. N., Greenlee, S., Skotte, N., et al. (2011). Potent and selective antisense oligonucleotides targeting single-nucleotide polymorphisms in the Huntington disease gene/allele-specific silencing of mutant huntingtin. Mol. Ther. 19, 2178-2185. doi: 10.1038/mt.2011.201

Chen, J., Sun, M., Kent, W. J., Huang, X., Xie, H., Wang, W., et al. (2004). Over $20 \%$ of human transcripts might form sense-antisense pairs. Nucleic Acids Res. 32, 4812-4820. doi: 10.1093/nar/gkh818

Cho, D. H., Thienes, C. P., Mahoney, S. E., Analau, E., Filippova, G. N., and Tapscott, S. J. (2005). Antisense transcription and heterochromatin at the DM1 CTG repeats are constrained by CTCF. Mol. Cell 20, 483-489. doi: 10.1016/j.molcel.2005.09.002

Chung, D. W., Rudnicki, D. D., Yu, L., and Margolis, R. L. (2011). A natural antisense transcript at the Huntington's disease repeat locus regulates HTT expression. Hum. Mol. Genet. 20, 3467-3477. doi: 10.1093/hmg/ddr263

Clabough, E. B. (2013). Huntington's disease: the past, present, and future search for disease modifiers. Yale J. Biol. Med. 86, 217-233.

Daughters, R. S., Tuttle, D. L., Gao, W., Ikeda, Y., Moseley, M. L., Ebner, T. J., et al. (2009). RNA gain-of-function in spinocerebellar ataxia type 8. PLoS Genet. 5:e1000600. doi: 10.1371/journal.pgen. 1000600

Day, J. W., Schut, L. J., Moseley, M. L., Durand, A. C., and Ranum, L. P. (2000). Spinocerebellar ataxia type 8: clinical features in a large family. Neurology 55, 649-657. doi: 10.1212/WNL.55.5.649

de Almeida, L. P., Zala, D., Aebischer, P., and Deglon, N. (2001). Neuroprotective effect of a CNTF-expressing lentiviral vector in the quinolinic acid rat model of Huntington's disease. Neurobiol. Dis. 8, 433-446. doi: 10.1006/nbdi.2001.0388

de Mezer, M., Wojciechowska, M., Napierala, M., Sobczak, K., and Krzyzosiak, W. J. (2011). Mutant CAG repeats of Huntingtin transcript fold into hairpins, form nuclear foci and are targets for RNA interference. Nucleic Acids Res. 39, 3852-3863. doi: 10.1093/nar/gkq1323

Derrien, T., Johnson, R., Bussotti, G., Tanzer, A., Djebali, S., Tilgner, H., et al. (2012). The GENCODE v7 catalog of human long noncoding RNAs: analysis of their gene structure, evolution, and expression. Genome Res. 22, 1775-1789. doi: $10.1101 /$ gr.132159.111

Ellegren, H. (2004). Microsatellites: simple sequences with complex evolution. Nat. Rev. Genet. 5, 435-445. doi: 10.1038/nrg1348

Esteller, M. (2011). Non-coding RNAs in human disease. Nat. Rev. Genet. 12, 861-874. doi: 10.1038/nrg3074

Fernandez-Costa, J. M., Garcia-Lopez, A., Zuñiga, S., Fernandez-Pedrosa, V., Felipo-Benavent, A., Mata, M., et al. (2013). Expanded CTG repeats trigger miRNA alterations in Drosophila that are conserved in myotonic dystrophy type 1 patients. Hum. Mol. Genet. 22, 704-716. doi: 10.1093/hmg/dds478

Fiszer, A., Olejniczak, M., Switonski, P. M., Wroblewska, J. P., Wisniewska-Kruk, J., Mykowska, A., et al. (2012). An evaluation of oligonucleotide-based therapeutic strategies for polyQ diseases. BMC Mol. Biol. 13:6. doi: 10.1186/1471-2199-13-6

Fugier, C., Klein, A. F., Hammer, C., Vassilopoulos, S., Ivarsson, Y., Toussaint, A., et al. (2011). Misregulated alternative splicing of BIN1 is associated with T tubule alterations and muscle weakness in myotonic dystrophy. Nat. Med. 17, 720-725. doi: $10.1038 / \mathrm{nm} .2374$

Fukuda, T., Yamagata, K., Fujiyama, S., Matsumoto, T., Koshida, I., Yoshimura, K., et al. (2007). DEAD-box RNA helicase subunits of the Drosha complex are required for processing of rRNA and a subset of microRNAs. Nat. Cell Biol. 9, 604-611. doi: 10.1038/ncb1577

Gagnon, K. T., Pendergraff, H. M., Deleavey, G. F., Swayze, E. E., Potier, P., Randolph, J., et al. (2010). Allele-selective inhibition of mutant huntingtin expression with antisense oligonucleotides targeting the expanded CAG repeat. Biochemistry 49, 10166-10178. doi: 10.1021/bi101208k

Galka-Marciniak, P., Urbanek, M. O., and Krzyzosiak, W. J. (2012). Triplet repeats in transcripts: structural insights into RNA toxicity. Biol. Chem. 393, 1299-1315. doi: 10.1515/hsz-2012-0218

Godin, J. D., Colombo, K., Molina-Calavita, M., Keryer, G., Zala, D., Charrin, B. C., et al. (2010). Huntingtin is required for mitotic spindle orientation and mammalian neurogenesis. Neuron 67, 392-406. doi: 10.1016/j.neuron.2010.06.027

Gomes-Pereira, M., Foiry, L., Nicole, A., Huguet, A., Junien, C., Munnich, A., et al. (2007). CTG trinucleotide repeat "big jumps": large expansions, small mice. PLoS Genet. 3:e52. doi: 10.1371/journal.pgen.0030052

Gray, S. G. (2010). Targeting histone deacetylases for the treatment of Huntington's disease. CNS Neurosci. Ther. 16, 348-361 doi: 10.1111/j.1755-5949.2010.00184.x Gregory, R. I., Yan, K. P., Amuthan, G., Chendrimada, T., Doratotaj, B., Cooch, N., et al. (2004). The microprocessor complex mediates the genesis of microRNAs. Nature 432, 235-240. doi: 10.1038/nature03120

Hagerman, P. J., and Hagerman, R. J. (2004). The Fragile-X premutation: a maturing perspective. Am. J. Hum. Genet. 75, 352.

Handa, V., Saha, T., and Usdin, K. (2003). The fragile X syndrome repeats form RNA hairpins that do not activate the interferon-inducible protein kinase, PKR, but are cut by Dicer. Nucleic Acids Res. 31, 6243-6248. doi: 10.1093/nar/ gkg818

Haramati, S., Chapnik, E., Sztainberg, Y., Eilam, R., Zwang, R., Gershoni, N., et al. (2010). miRNA malfunction causes spinal motor neuron disease. Proc. Natl. Acad. Sci. U.S.A. 107, 13111-13116. doi: 10.1073/pnas.1006151107

Harper, S. Q., Staber, P. D., He, X., Eliason, S. L., Martins, I. H., Mao, Q., et al. (2005). RNA interference improves motor and neuropathological abnormalities in a Huntington's disease mouse model. Proc. Natl. Acad. Sci. U.S.A. 102, 5820 5825. doi: 10.1073/pnas.0501507102

He, Y., Vogelstein, B., Velculescu, V. E., Papadopoulos, N., and Kinzler, K. W. (2008). The antisense transcriptomes of human cells. Science 322, 1855-1857. doi: 10.1126/science.1163853

Holmes, S. E., O’Hearn, E., Rosenblatt, A., Callahan, C., Hwang, H. S., IngersollAshworth, R. G., et al. (2001). A repeat expansion in the gene encoding junctophilin-3 is associated with Huntington disease-like 2. Nat. Genet. 29, 377-378. doi: 10.1038/ng760

Hsu, R. J., Hsiao, K. M., Lin, M. J., Li, C. Y., Wang, L. C., Chen, L. K., et al. (2011). Long tract of untranslated CAG repeats is deleterious in transgenic mice. PLoS ONE 6:e16417. doi: 10.1371/journal.pone.0016417

Hu, J., Dodd, D. W., Hudson, R. H., and Corey, D. R. (2009a). Cellular localization and allele-selective inhibition of mutant huntingtin protein by 
peptide nucleic acid oligomers containing the fluorescent nucleobase [bis-o(aminoethoxy)phenyl]pyrrolocytosine. Bioorg. Med. Chem. Lett. 19, 6181-6184. doi: 10.1016/j.bmcl.2009.09.004

Hu, J., Matsui, M., and Corey, D. R. (2009b). Allele-selective inhibition of mutant huntingtin by peptide nucleic acid-peptide conjugates, locked nucleic acid, and small interfering RNA. Ann. N. Y. Acad. Sci. 1175, 24-31. doi: 10.1111/j.17496632.2009.04975.x

Hu, J., Matsui, M., Gagnon, K. T., Schwartz, J. C., Gabillet, S., Arar, K., et al. $(2009 \mathrm{c})$. Allele-specific silencing of mutant huntingtin and ataxin-3 genes by targeting expanded CAG repeats in mRNAs. Nat. Biotechnol. 27, 478-484. doi: $10.1038 /$ nbt. 1539

Huang, K., Sanders, S. S., Kang, R., Carroll, J. B., Sutton, L., Wan, J., et al. (2011). Wild-type HTT modulates the enzymatic activity of the neuronal palmitoyl transferase HIP14. Hum. Mol. Genet. 20, 3356-3365. doi: $10.1093 / \mathrm{hmg} /$ breakddr242

Huguet, A., Medja, F., Nicole, A., Vignaud, A., Guiraud-Dogan, C., Ferry, A., et al. (2012). Molecular, physiological, and motor performance defects in DMSXL mice carrying $>1,000$ CTG repeats from the human DM1 locus. PLoS Genet. 8:e1003043. doi: 10.1371/journal.pgen.1003043

Iwahashi, C. K., Yasui, D. H., An, H. J., Greco, C. M., Tassone, F., Nannen, K., et al. (2006). Protein composition of the intranuclear inclusions of FXTAS. Brain 129, 256-271. doi: 10.1093/brain/awh650

Jiang, H., Mankodi, A., Swanson, M. S., Moxley, R. T., and Thornton, C. A. (2004). Myotonic dystrophy type 1 is associated with nuclear foci of mutant RNA, sequestration of muscleblind proteins and deregulated alternative splicing in neurons. Hum. Mol. Genet. 13, 3079-3088. doi: 10.1093/hmg/ddh327

Jin, P., Duan, R., Qurashi, A., Qin, Y., Tian, D., Rosser, T. C., et al. (2007). Pur alpha binds to rCGG repeats and modulates repeat-mediated neurodegeneration in a Drosophila model of fragile X tremor/ataxia syndrome. Neuron 55, 556-564. doi: 10.1016/j.neuron.2007.07.020

Karres, J. S., Hilgers, V., Carrera, I., Treisman, J., and Cohen, S. M. (2007). The conserved microRNA miR-8 tunes atrophin levels to prevent neurodegeneration in Drosophila. Cell 131, 136-145. doi: 10.1016/j.cell.2007.09.020

Khalili, K., Del Valle, L., Muralidharan, V., Gault, W. J., Darbinian, N., Otte, J., et al. (2003). Puralpha is essential for postnatal brain development and developmentally coupled cellular proliferation as revealed by genetic inactivation in the mouse. Mol. Cell. Biol. 23, 6857-6875. doi: 10.1128/MCB.23.19.6857-6875.2003

Kim, J., Inoue, K., Ishii, J., Vanti, W. B., Voronov, S. V., Murchison, E., et al. (2007). A MicroRNA feedback circuit in midbrain dopamine neurons. Science 317, 12201224. doi: 10.1126/science.1140481

Koob, M. D., Moseley, M. L., Schut, L. J., Benzow, K. A., Bird, T. D., Day, J. W., et al. (1999). An untranslated CTG expansion causes a novel form of spinocerebellar ataxia (SCA8). Nat. Genet. 21, 379-384. doi: 10.1038/7710

Kordasiewicz, H. B., Stanek, L. M., Wancewicz, E. V., Mazur, C., McAlonis, M. M., Pytel, K. A., et al. (2012). Sustained therapeutic reversal of Huntington's disease by transient repression of huntingtin synthesis. Neuron 74, 1031-1044. doi: 10.1016/j.neuron.2012.05.009

Krol, J., Fiszer, A., Mykowska, A., Sobczak, K., de Mezer, M., and Krzyzosiak, W. J. (2007). Ribonuclease dicer cleaves triplet repeat hairpins into shorter repeats that silence specific targets. Mol. Cell 25, 575-586. doi: 10.1016/j.molcel.2007. 01.031

Krzyzosiak, W. J., Sobczak, K., Wojciechowska, M., Fiszer, A., Mykowska, A., and Kozlowski, P. (2012). Triplet repeat RNA structure and its role as pathogenic agent and therapeutic target. Nucleic Acids Res. 40, 11-26. doi: 10.1093/nar/ gkr729

Kuyumcu-Martinez, N. M., Wang, G. S., and Cooper, T. A. (2007). Increased steady-state levels of CUGBP1 in myotonic dystrophy 1 are due to PKC-mediated hyperphosphorylation. Mol. Cell 28, 68-78. doi: 10.1016/j.molcel.2007.07.027

Ladd, P. D., Smith, L. E., Rabaia, N. A., Moore, J. M., Georges, S. A., Hansen, R. S., et al. (2007). An antisense transcript spanning the CGG repeat region of FMR1 is upregulated in premutation carriers but silenced in full mutation individuals. Hum. Mol. Genet. 16, 3174-3187. doi: 10.1093/hmg/ddm293

Laurent, F. X., Sureau, A., Klein, A. F., Trouslard, F., Gasnier, E., Furling, D., et al. (2012). New function for the RNA helicase p68/DDX5 as a modifier of MBNL1 activity on expanded CUG repeats. Nucleic Acids Res. 40, 3159-3171. doi: $10.1093 /$ nar/gkr1228

Lawlor, K. T., O’Keefe, L. V., Samaraweera, S. E., van Eyk, C. L., McLeod, C. J., Maloney, C. A., et al. (2011). Double-stranded RNA is pathogenic in Drosophila models of expanded repeat neurodegenerative diseases. Hum. Mol. Genet. 20, 3757-3768. doi: 10.1093/hmg/ddr292

Lee, Y., Samaco, R. C., Gatchel, J. R., Thaller, C., Orr, H. T., and Zoghbi, H. Y. (2008). miR-19, miR-101 and miR-130 co-regulate ATXN1 levels to potentially modulate SCA1 pathogenesis. Nat. Neurosci. 11, 1137-1139. doi: 10.1038/nn.2183

Li, L. B., Yu, Z., Teng, X., and Bonini, N. M. (2008). RNA toxicity is a component of ataxin-3 degeneration in Drosophila. Nature 453, 1107-1111. doi: 10.1038 /nature06909

Li, Y., Yokota, T., Matsumura, R., Taira, K., and Mizusawa, H. (2004). Sequencedependent and independent inhibition specific for mutant ataxin-3 by small interfering RNA. Ann. Neurol. 56, 124-129. doi: 10.1002/ana.20141

Liu, N., Landreh, M., Cao, K., Abe, M., Hendriks, G. J., Kennerdell, J. R., et al. (2012). The microRNA miR-34 modulates ageing and neurodegeneration in Drosophila. Nature 482, 519-523. doi: 10.1038/nature10810

Loesch, D. Z., Godler, D. E., Evans, A., Bui, Q. M., Gehling, F., Kotschet, K. E., et al. (2011). Evidence for the toxicity of bidirectional transcripts and mitochondrial dysfunction in blood associated with small CGG expansions in the FMR1 gene in patients with parkinsonism. Genet. Med. 13, 392-399. doi: 10.1097/GIM.0b013e3182064362

Lombardi, M. S., Jaspers, L., Spronkmans, C., Gellera, C., Taroni, F., Di Maria, E., et al. (2009). A majority of Huntington's disease patients may be treatable by individualized allele-specific RNA interference. Exp. Neurol. 217, 312-319. doi: 10.1016/j.expneurol.2009.03.004

Mahishi, L. H., Hart, R. P., Lynch, D. R., and Ratan, R. R. (2012). miR-886$3 \mathrm{p}$ levels are elevated in Friedreich ataxia. J. Neurosci. 32, 9369-9373. doi: 10.1523/JNEUROSCI.0059-12.2012

Martí, E., Pantano, L., Banez-Coronel, M., Llorens, F., Minones-Moyano, E., Porta, S., et al. (2010). A myriad of miRNA variants in control and Huntington's disease brain regions detected by massively parallel sequencing. Nucleic Acids Res. 38, 7219-7235. doi: 10.1093/nar/gkq575

McBride, J. L., Boudreau, R. L., Harper, S. Q., Staber, P. D., Monteys, A. M., Martins, I., et al. (2008). Artificial miRNAs mitigate shRNA-mediated toxicity in the brain: implications for the therapeutic development of RNAi. Proc. Natl. Acad. Sci. U.S.A. 105, 5868-5873. doi: 10.1073/pnas.0801775105

McCann, C., Holohan, E. E., Das, S., Dervan, A., Larkin, A., Lee, J. A., et al. (2011). The Ataxin-2 protein is required for microRNA function and synapse-specific long-term olfactory habituation. Proc. Natl. Acad. Sci. U.S.A. 108, E655-E662. doi: 10.1073/pnas.1107198108

Mittoux, V., Joseph, J. M., Conde, F., Palfi, S., Dautry, C., Poyot, T., et al. (2000). Restoration of cognitive and motor functions by ciliary neurotrophic factor in a primate model of Huntington's disease. Hum. Gene Ther. 11, 1177-1187. doi: $10.1089 / 10430340050015220$

Morris, K. V., Santoso, S., Turner, A. M., Pastori, C., and Hawkins, P. G. (2008). Bidirectional transcription directs both transcriptional gene activation and suppression in human cells. PLoS Genet. 4:e1000258. doi: 10.1371/journal.pgen.1000258

Moseley, M. L., Zu, T., Ikeda, Y., Gao, W., Mosemiller, A. K., Daughters, R. S., et al. (2006). Bidirectional expression of CUG and CAG expansion transcripts and intranuclear polyglutamine inclusions in spinocerebellar ataxia type 8. Nat. Genet. 38, 758-769. doi: 10.1038/ng1827

Mulders, S. A., van den Broek, W. J., Wheeler, T. M., Croes, H. J., van KuikRomeijn, P., de Kimpe, S. J., et al. (2009). Triplet-repeat oligonucleotide-mediated reversal of RNA toxicity in myotonic dystrophy. Proc. Natl. Acad. Sci. U.S.A. 106, 13915-13920. doi: 10.1073/pnas.0905780106

Mykowska, A., Sobczak, K., Wojciechowska, M., Kozlowski, P., and Krzyzosiak, W. J. (2011). CAG repeats mimic CUG repeats in the misregulation of alternative splicing. Nucleic Acids Res. 39, 8938-8951. doi: 10.1093/nar/gkr608

O'Carroll, D., and Schaefer, A. (2013). General principals of miRNA biogenesis and regulation in the brain. Neuropsychopharmacology 38, 39-54. doi: 10.1038/npp.2012.87

Omi, K., Hachiya, N. S., Tokunaga, K., and Kaneko, K. (2005). siRNA-mediated inhibition of endogenous Huntington disease gene expression induces an aberrant configuration of the ER network in vitro. Biochem. Biophys. Res. Commun. 338, 1229-1235. doi: 10.1016/j.bbrc.2005.10.061

Orr, H. T., and Zoghbi, H. Y. (2007). Trinucleotide repeat disorders. Annu. Rev. Neurosci. 39, 373-379. doi: 10.1146/annurev.neuro.29.051605.113042

Packer, A. N., Xing, Y., Harper, S. Q., Jones, L., and Davidson, B. L. (2008). The bifunctional microRNA miR-9/miR-9* regulates REST and CoREST and 
is downregulated in Huntington's disease. J. Neurosci. 28, 14341-14346. doi: 10.1523/JNEUROSCI.2390-08.2008

Perez-Navarro, E., Canudas, A. M., Akerund, P., Alberch, J., and Arenas, E. (2000). Brain-derived neurotrophic factor, neurotrophin-3, and neurotrophin-4/5 prevent the death of striatal projection neurons in a rodent model of Huntington's disease. J. Neurochem. 75, 2190-2199. doi: 10.1046/j.1471-4159.2000.0752190.x

Persengiev, S., Kondova, I., Otting, N., Koeppen, A. H., and Bontrop, R. E. (2011). Genome-wide analysis of miRNA expression reveals a potential role for miR-144 in brain aging and spinocerebellar ataxia pathogenesis. Neurobiol. Aging 32, 2316, e2317-e2327. doi: 10.1016/j.neurobiolaging.2010.03.014

Pfister, E. L., Kennington, L., Straubhaar, J., Wagh, S., Liu, W., DiFiglia, M., et al. (2009). Five siRNAs targeting three SNPs may provide therapy for three-quarters of Huntington's disease patients. Curr. Biol. 19, 774-778. doi: 10.1016/j.cub.2009.03.030

Pouladi, M. A., Stanek, L. M., Xie, Y., Franciosi, S., Southwell, A. L., Deng, Y., et al. (2012). Marked differences in neurochemistry and aggregates despite similar behavioural and neuropathological features of Huntington disease in the full-length BACHD and YAC128 mice. Hum. Mol. Genet. 21, 2219-2232. doi: 10.1093/hmg/dds037

Ranum, L. P., and Cooper, T. A. (2006). RNA-mediated neuromuscular disorders. Annu. Rev. Neurosci. 29, 259-277. doi: 10.1146/annurev.neuro.29.051605.113014

Rau, F., Freyermuth, F., Fugier, C., Villemin, J. P., Fischer, M. C., Jost, B., et al. (2011). Misregulation of miR-1 processing is associated with heart defects in myotonic dystrophy. Nat. Struct. Mol. Biol. 18, 840-845. doi: 10.1038/nsmb.2067

Rodriguez-Lebron, E., Denovan-Wright, E. M., Nash, K., Lewin, A. S., and Mandel, R. J. (2005). Intrastriatal rAAV-mediated delivery of anti-huntingtin shRNAs induces partial reversal of disease progression in R6/1 Huntington's disease transgenic mice. Mol. Ther. 12, 618-633. doi: 10.1016/j.ymthe.2005.05.006

Rodriguez-Lebron, E., Liu, G., Keiser, M., Behlke, M. A., and Davidson, B. L. (2013). Altered Purkinje cell miRNA expression and SCA1 pathogenesis. Neurobiol. Dis. 54, 456-463. doi: 10.1016/j.nbd.2013. 01.019

Rudnicki, D. D., Holmes, S. E., Lin, M. W., Thornton, C. A., Ross, C. A., and Margolis, R. L. (2007). Huntington's disease - like 2 is associated with CUG repeat-containing RNA foci. Ann. Neurol. 61, 272-282. doi: 10.1002/ana.21081

Sah, D. W., and Aronin, N. (2011). Oligonucleotide therapeutic approaches for Huntington disease. J. Clin. Invest. 121, 500-507. doi: 10.1172/JCI45130

Savas, J. N., Makusky, A., Ottosen, S., Baillat, D., Then, F., Krainc, D., et al. (2008). Huntington's disease protein contributes to RNA-mediated gene silencing through association with Argonaute and P bodies. Proc. Natl. Acad. Sci. U.S.A. 105, 10820-10825. doi: 10.1073/pnas.0800658105

Schaefer, A., O’Carroll, D., Tan, C. L., Hillman, D., Sugimori, M., Llinas, R., et al. (2007). Cerebellar neurodegeneration in the absence of microRNAs. J. Exp. Med. 204, 1553-1558. doi: 10.1084/jem.20070823

Scholefield, J., Greenberg, L. J., Weinberg, M. S., Arbuthnot, P. B., Abdelgany, A., and Wood, M. J. (2009). Design of RNAi hairpins for mutation-specific silencing of ataxin-7 and correction of a SCA7 phenotype. PLoS ONE 4:e7232. doi: 10.1371/journal.pone.0007232

Schwarz, D. S., Ding, H., Kennington, L., Moore, J. T., Schelter, J., Burchard, J., et al. (2006). Designing siRNA that distinguish between genes that differ by a single nucleotide. PLoS Genet. 2:e140. doi: 10.1371/journal.pgen.0020140

Seixas, A. I., Holmes, S. E., Takeshima, H., Pavlovich, A., Sachs, N., Pruitt, J. L., et al. (2012). Loss of junctophilin-3 contributes to Huntington disease-like 2 pathogenesis. Ann. Neurol. 71, 245-257. doi: 10.1002/ana.22598

Sellier, C., Freyermuth, F., Tabet, R., Tran, T., He, F., Ruffenach, F., et al. (2013). Sequestration of DROSHA and DGCR8 by expanded CGG RNA repeats alters microRNA processing in fragile X-associated tremor/ataxia syndrome. Cell Rep. 3, 869-880. doi: 10.1016/j.celrep.2013.02.004

Sellier, C., Rau, F., Liu, Y., Tassone, F., Hukema, R. K., Gattoni, R., et al. (2010). Sam68 sequestration and partial loss of function are associated with splicing alterations in FXTAS patients. EMBO J. 29, 1248-1261. doi: 10.1038/emboj.2010.21

Shin, D., Shin, J. Y., McManus, M. T., Ptacek, L. J., and Fu, Y. H. (2009). Dicer ablation in oligodendrocytes provokes neuronal impairment in mice. Ann. Neurol. 66, 843-857. doi: 10.1002/ana.21927

Shiohama, A., Sasaki, T., Noda, S., Minoshima, S., and Shimizu, N. (2003). Molecular cloning and expression analysis of a novel gene DGCR8 located in the DiGeorge syndrome chromosomal region. Biochem. Biophys. Res. Commun. 304, 184-190. doi: 10.1016/S0006-291X(03)00554-0
Sofola, O. A., Jin, P., Qin, Y., Duan, R., Liu, H., de Haro, M., et al. (2007). RNA-binding proteins hnRNP A2/B1 and CUGBP1 suppress fragile X CGG premutation repeat-induced neurodegeneration in a Drosophila model of FXTAS. Neuron 55, 565-571. doi: 10.1016/j.neuron.2007.07.021

Sopher, B. L., Ladd, P. D., Pineda, V. V., Libby, R. T., Sunkin, S. M., Hurley, J. B., et al. (2011). CTCF regulates ataxin-7 expression through promotion of a convergently transcribed, antisense noncoding RNA. Neuron 70, 1071-1084. doi: 10.1016/j.neuron.2011.05.027

Southwell, A. L., Ko, J., and Patterson, P. H. (2009). Intrabody gene therapy ameliorates motor, cognitive, and neuropathological symptoms in multiple mouse models of Huntington's disease. J. Neurosci. 29, 13589-13602. doi: 10.1523/JNEUROSCI.4286-09.2009

Stark, K. L., Xu, B., Bagchi, A., Lai, W. S., Liu, H., Hsu, R., et al. (2008). Altered brain microRNA biogenesis contributes to phenotypic deficits in a 22q11-deletion mouse model. Nat. Genet. 40, 751-760. doi: 10.1038/ng.138

Steffan, J. S., Bodai, L., Pallos, J., Poelman, M., McCampbell, A., Apostol, B. L., et al. (2001). Histone deacetylase inhibitors arrest polyglutamine-dependent neurodegeneration in Drosophila. Nature 413, 739-743. doi: 10.1038/35099568

Tao, J., Wu, H., Lin, Q., Wei, W., Lu, X. H., Cantle, J. P., et al. (2011). Deletion of astroglial Dicer causes non-cell-autonomous neuronal dysfunction and degeneration. J. Neurosci. 31, 8306-8319. doi: 10.1523/JNEUROSCI.0567-11.2011

Todd, P. K., Oh, S. Y., Krans, A., He, F., Sellier, C., Frazer, M., et al. (2013). CGG repeat-associated translation mediates neurodegeneration in fragile $\mathrm{X}$ tremor ataxia syndrome. Neuron 78, 440-455. doi: 10.1016/j.neuron.2013.03.026

Verkerk, A. J., Pieretti, M., Sutcliffe, J. S., Fu, Y. H., Kuhl, D. P., Pizzuti, A., et al. (1991). Identification of a gene (FMR-1) containing a CGG repeat coincident with a breakpoint cluster region exhibiting length variation in fragile $\mathrm{X}$ syndrome. Cell 65, 905-914. doi: 10.1016/0092-8674(91)90397-H

Wang, L. C., Chen, K. Y., Pan, H., Wu, C. C., Chen, P. H., Liao, Y. T., et al. (2011). Muscleblind participates in RNA toxicity of expanded CAG and CUG repeats in Caenorhabditis elegans. Cell. Mol. Life Sci 68, 1255-1267. doi: 10.1007/s00018010-0522-4

Warby, S. C., Montpetit, A., Hayden, A. R., Carroll, J. B., Butland, S. L., Visscher, H., et al. (2009). CAG expansion in the Huntington disease gene is associated with a specific and targetable predisposing haplogroup. Am. J. Hum. Genet. 84, 351-366. doi: 10.1016/j.ajhg.2009.02.003

Watts, J. K., and Corey, D. R. (2012). Silencing disease genes in the laboratory and the clinic. J. Pathol. 226, 365-379. doi: 10.1002/path.2993

Wheeler, T. M., Leger, A. J., Pandey, S. K., MacLeod, A. R., Nakamori, M., Cheng, S. H., et al. (2012). Targeting nuclear RNA for in vivo correction of myotonic dystrophy. Nature 488, 111-115. doi: 10.1038/nature11362

Wheeler, T. M., and Thornton, C. A. (2007). Myotonic dystrophy: RNA-mediated muscle disease. Curr. Opin. Neurol 20, 572-576. doi: 10.1097/WCO.0b013e3282ef6064

Wilburn, B., Rudnicki, D. D., Zhao, J., Weitz, T. M., Cheng, Y., Gu, X., et al. (2011). An antisense CAG repeat transcript at JPH3 locus mediates expanded polyglutamine protein toxicity in Huntington's disease-like 2 mice. Neuron 70, 427-440. doi: 10.1016/j.neuron.2011.03.021

Xu, S., Zhang, R., Niu, J., Cui, D., Xie, B., Zhang, B., et al. (2012). Oxidative stress mediated-alterations of the microRNA expression profile in mouse hippocampal neurons. Int. J. Mol. Sci. 13, 16945-16960. doi: 10.3390/ijms131216945

Yanagisawa, H., Bundo, M., Miyashita, T., Okamura-Oho, Y., Tadokoro, K., Tokunaga, K., et al. (2000). Protein binding of a DRPLA family through arginineglutamic acid dipeptide repeats is enhanced by extended polyglutamine. Hum. Mol. Genet. 9, 1433-1442. doi: 10.1093/hmg/9.9.1433

Yu, D., Pendergraff, H., Liu, J., Kordasiewicz, H. B., Cleveland, D. W., Swayze, E. E., et al. (2012). Single-stranded RNAs use RNAi to potently and alleleselectively inhibit mutant huntingtin expression. Cell 150, 895-908. doi: 10.1016/j.cell.2012.08.002

Yu, W., Gius, D., Onyango, P., Muldoon-Jacobs, K., Karp, J., Feinberg, A. P., et al. (2008). Epigenetic silencing of tumour suppressor gene $\mathrm{p} 15$ by its antisense RNA. Nature 451, 202-206. doi: 10.1038/nature06468

Yu, Z., Teng, X., and Bonini, N. M. (2011). Triplet repeat-derived siRNAs enhance RNA-mediated toxicity in a Drosophila model for myotonic dystrophy. PLoS Genet. 7:e1001340. doi: 10.1371/journal.pgen.1001340

Yuan, Y., Compton, S. A., Sobczak, K., Stenberg, M. G., Thornton, C. A., Griffith, J. D., et al. (2007). Muscleblind-like 1 interacts with RNA hairpins in splicing target and pathogenic RNAs. Nucleic Acids Res. 35, 5474-5486. doi: 10.1093/nar/gkm601 
Zheng, Z., and Diamond, M. I. (2012). Huntington disease and the huntingtin protein. Prog. Mol. Biol. Transl. Sci. 107, 189-214. doi: 10.1016/B978-0-12385883-2.00010-2

Zongaro, S., Hukema, R., D’Antoni, S., Davidovic, L., Barbry, P., Catania, M. V., et al. (2013). The $3^{\prime}$ UTR of FMR1 mRNA is a target of miR-101, miR-129-5p and miR-221: implications for the molecular pathology of FXTAS at the synapse. Hum. Mol. Genet. 22, 1971-1982. doi: 10.1093/hmg/ddt044

Zu, T., Gibbens, B., Doty, N. S., Gomes-Pereira, M., Huguet, A., Stone, M. D., et al. (2011). Non-ATG-initiated translation directed by microsatellite expansions. Proc. Natl. Acad. Sci. U.S.A. 108, 260-265. doi: 10.1073/pnas.1013343108

Conflict of Interest Statement: The authors declare that the research was conducted in the absence of any commercial or financial relationships that could be construed as a potential conflict of interest.
Received: 12 August 2013; accepted: 12 November 2013; published online: 03 December 2013.

Citation: Martí E and Estivill X (2013) Small non-coding RNAs add complexity to the RNA pathogenic mechanisms in trinucleotide repeat expansion diseases. Front. Mol. Neurosci. 6:45. doi: 10.3389/fnmol.2013. 00045

This article was submitted to the journal Frontiers in Molecular Neuroscience.

Copyright (c) 2013 Marti and Estivill. This is an open-access article distributed under the terms of the Creative Commons Attribution License (CC BY). The use, distribution or reproduction in other forums is permitted, provided the original author(s) or licensor are credited and that the original publication in this journal is cited, in accordance with accepted academic practice. No use, distribution or reproduction is permitted which does not comply with these terms. 